\title{
Case study on stratospheric and mesospheric concentric gravity waves generated by deep convection
}

\author{
GuoChun Shi ${ }^{1,3}$, Xiong Hu' ${ }^{1}$, ZhiGang Yao ${ }^{2 *}$, WenJie Guo', MingChen Sun ${ }^{1,3}$, and XiaoYan Gong ${ }^{1}$ \\ ${ }^{1}$ National Space Science Center, Chinese Academy of Sciences, Beijing 100190, China; \\ ${ }^{2}$ Beijing Institution of Applied Meteorology, Beijing 100029, China; \\ ${ }^{3}$ University of Chinese Academy of Sciences, Beijing 100049, China

\section{Key Points:} \\ - The critical conditions of the based-ground phase speed and the background wind speed in multiple propagation directions to \\ calculate the parameter characteristics of the gravity wave is proposed. \\ - The value of based-ground phase speed mainly depends on the change of the tropopause wind speed. \\ - Gravity waves detected by the AIRS and DNB are generated by the same convective system.
}

Citation: Shi, G. C., Hu, X., Yao, Z. G., Guo, W. J., Sun, M. C. and Gong, X. Y. (2021). Case study on stratospheric and mesospheric concentric gravity waves generated by deep convection. Earth Planet. Phys., 5(1), 79-89. http://doi.org/10.26464/epp2021002

\begin{abstract}
Concentric gravity waves (CGWs) in the middle and upper atmosphere show wave-coupling processes between the lower atmosphere and the middle and upper atmosphere. In this research, we analyzed a case of CGWs detected simultaneously by the AIRS (Atmospheric Infrared Sounder) and the VIIRS/DNB (Day/Night Band of the Visible Infrared Imager Radiometer Suite) in the stratosphere and mesosphere. Results showed that gravity waves (GWs) were generated by the collocated Hurricane Bejisa on the island of Mauritius. The AIRS data showed arc-like phase fronts of GWs with horizontal wavelengths of 190 and $150 \mathrm{~km}$ at 21:08 coordinated universal time (UTC) on 1 January 2014 and at 10:00 UTC on 2 January 2014, whereas the DNB observed arced GWs with horizontal wavelengths of 60 and $150 \mathrm{~km}$ in the same geographic regions at 22:24 UTC. The characteristics of CGW parameters in the stratosphere ( 40 km) and the mesosphere $(\sim 87 \mathrm{~km})$, such as the vertical wavelength, intrinsic frequency, and intrinsic horizontal phase speed, were first derived together with the background winds from ERA5 reanalysis data and Horizontal Wind Model data through the dispersion relationship of GWs and the wind-filtering theory.
\end{abstract}

Keywords: concentric gravity waves; wavelength; intrinsic frequency; phase speed

\section{Introduction}

Gravity waves (GWs) have been identified as one of the most important dynamic processes in the atmosphere. They have a significant effect on the structure and stability of atmospheric circulation (Charron and Manzini, 2002; Alexander et al., 2010) and play an important role in defining the wind, temperature, and vertical coupling of the atmosphere (Fritts and Alexander, 2003; Kaifler et al., 2015; Xu S et al., 2019). Deep convection, such as with thunderstorms, mesoscale convective complexes, and mesoscale convective systems, is believed to be the major source of GWs (Hoffmann and Alexander, 2010; Gong J et al., 2015; Perwitasari et al., 2016). Hurricanes (maximum wind speed of $32.7 \mathrm{~m} \cdot \mathrm{s}^{-1}$, wind level 12), as strong tropical cyclone systems with complex evolutionary processes and internal structures, may be particularly intense sources. Convection-generated GWs propagating in the troposphere, stratosphere, and mesosphere may contribute to the stratospheric

Correspondence to: Z. G. Yao, zhigangyao@mail.iap.ac.cn

Received 11 MAY 2020; Accepted 03 AUG 2020.

Accepted article online 21 SEP 2020.

C 2021 by Earth and Planetary Physics. quasi-biennial oscillation (Alexander and Holton, 1997; Piani et al., 2000; Huang KM et al., 2009), which modulates monsoonal precipitation; the Brewer-Dobson circulation (Alexander and Rosenlof, 2003; Stephan et al., 2016), which governs stratospheric ozone transport and mesosphere and lower thermosphere forcing and heating/cooling (Yamashita et al., 2010; Liu X et al., 2014); and secondary wave generation in the low and middle latitudes (Vadas and Becker, 2018; Vadas et al., 2018).

The characteristics of convection-generated GWs have been routinely observed by using airglow measurements in the mesosphere. Yue J et al. (2009) observed semiconcentric or concentric gravity waves (CGWs) generated by deep convective plumes in the lower atmosphere by using a ground-based full-sky hydroxyl airglow imager in the mesopause region (80 to $105 \mathrm{~km}$ ). With a nadir-viewing airglow imager, these convection-generated GWs appear as circular rings traveling outward away from the center of the cone (Yue J et al., 2009; Miller et al., 2012; Yue J et al., 2014). Suzuki et al. (2013) used a ground-based airglow imager to observe a typhoon-generated GW with in the mesopause and estimated the horizontal wavelength, horizontal phase speed, and wave period as $34.5 \mathrm{~km}, 50.2 \mathrm{~m} \cdot \mathrm{s}^{-1}$, and $11.5 \mathrm{~min}$, respectively. 
Over the last decade or so, many three-dimensional spatial numerical models and nonlinear and linear models have simulated GWs generated by convection, and the characteristics of GWs have been further studied (Alexander et al., 2004; Vadas and Fritts, 2009). Because numerical simulation can yield a large quantity of high spatiotemporal resolution output results, researchers have increasingly adopted the Weather Research and Forecasting (WRF) model and the three-dimensional mesoscale model (MM5) to research GWs (Kuester et al., 2008; Kim et al., 2009). Convectiongenerated GWs are observed in the lower stratosphere of the MM5 model at horizontal scales of $15-300 \mathrm{~km}$, vertical scales of 4-8 km, and intrinsic periods of approximately 20-100 min. Kim and Chun (2010) used the mesoscale numerical model WRF-ARW (Advanced Research WRF) to simulate GWs in the stratosphere generated by Typhoon Saomai and demonstrated that the dominant propagation directions were eastward, northeastward, and southeastward because westward waves were mostly filtered by the background wind. Heale et al. (2017) conducted numerical simulations of the background wind-filtering effects on the CGWs and found that the winds control the dominant directionality, amplitude, and morphology of concentric patterns at a given altitude. Equinox months generally have smaller wind amplitudes and variability and thus more concentric patterns of CGWs, whereas solstice months have winds and shears leading to more arc-like patterns of CGWs.

Compared with ground-based data, the earth-viewing polar-orbit satellite instruments for the middle and upper atmospheric GWs have the advantages of relatively high horizontal and vertical resolution and global coverage in regions where oceans and sounding data are scarce (Kim et al., 2009; Yue J et al., 2013). Satellite instrument observations have shown that GWs are highly localized, a feature that can be used to provide information on their sources (Alexander and Teitelbaum, 2007), especially whether the GWs in the stratosphere and the mesosphere have the same excitation source. Most recently, data from the Atmospheric Infrared Sounder (AIRS) instrument (Aumann et al., 2003) on the National Aeronautics and Space Administration (NASA) Aqua satellite were used to image GWs at an altitude of approximately $40 \mathrm{~km}$ (Alexander and Teitelbaum, 2007). The phenomena of CGWs have been simultaneously observed by the AIRS and the Day/Night Band (DNB) of the Visible Infrared Imager Radiometer Suite (VIIRS) detecting instruments in the stratosphere and mesosphere over the Indian Ocean (Yue J et al., 2014), but they have not given the parameters of the CGWs, such as the phase speed and period.

Because AIRS and VIIRS can provide a snapshot of the CGW images at a point in time but not the temporal variations of CGW images at a fixed location, it is difficult to obtain all the parameters of GWs with only satellite image data. To investigate the characteristics of CGWs in the satellite image data, background wind data and the wind-filtering theory were initially used in this research to derive the GW parameters. We attempted to use data from multiple satellites to investigate the characteristics of GW parameters generated by Hurricane Bejisa in the stratosphere and mesosphere. The characteristics of GW parameters at different heights were diagnosed in detail in conjunction with using background wind speed data to further understand the coupling process from the source regions to the upper atmospheric regions in the troposphere-stratosphere-mesosphere atmospheric system. In Section 2, we briefly describe Hurricane Bejisa, which occurred from 1 to 6 January 2014 on the island of Mauritius. In Section 3, we introduce the AIRS detectors on the Aqua satellite and the DNB detectors on the Suomi National Polar-orbiting Partnership (NPP) satellite as well as the ERA5 reanalysis data and Horizontal Wind Model (HWM) data used in this study. In Section 4, we provide an analysis of CGWs according to the dispersion relationship and the wind-filtering theory of CGWs in the stratosphere and mesosphere. Finally, we present our conclusions in Section 5.

\section{Description of Hurricane Bejisa}

Hurricane Bejisa is a powerful and deep tropical cyclone that reached Reunion Island and Mauritius Island in January 2014. The formation process was as follows: in late December 2013, under advantageous conditions, a tropical storm that occurred in northern Madagascar continued to develop and intensify into a mesoscale tropical storm on 29 December 2013. It then intensified rapidly and developed into a strong tropical cyclone that reached a peak maximum sustained wind speed of $165 \mathrm{~km} \cdot \mathrm{h}^{-1}$ on 30 December 2013. For most of the time, the hurricane moved in a south-southeast direction. Figure 1 shows the cloud images obtained via the Fengyun polar-orbiting satellite. At 18:20 UTC on 1 January 2014 (Figure 1a), the eye of the hurricane was at $\left(19.3^{\circ} \mathrm{S}\right.$, $53.6^{\circ} \mathrm{E}$ ), and the maximum speed was $144 \mathrm{~km} \cdot \mathrm{h}^{-1}$. At 05:30 UTC on 2 January 2014, it became a category 2 hurricane (Figure 1b). The hurricane reached category 3 when the eye of the hurricane was at $\left(20.4^{\circ} \mathrm{S}, 54.2^{\circ} \mathrm{E}\right)$, and it continued to move to the southeast. At 18:20 UTC, the eye was located at $\left(22.5^{\circ} \mathrm{S}, 55^{\circ} \mathrm{E}\right)$ (Figure $\left.1 \mathrm{C}\right)$, and on 3 January 2014, it turned southwest. Figure 2 shows the six-day trajectory of Hurricane Bejisa provided by the Japan Meteorological Agency. The white crosses indicate the eyes of the hurricane from 00:00 UTC on 1 January 2014 to 00:00 UTC on 6 January 2014. The four stages in the life span of the hurricane (tropical storm, hurricane, tropical depression, and extratropical cyclone) are shown by the orange, purple, red, and yellow portions of the trajectory, respectively.

\section{Data Sets}

To study the CGWs generated by deep convection, data from the AIRS and DNB were analyzed to determine the CGWs at different altitudes. The ERA5 reanalysis data and the HWM data were used to provide the background winds, with which the parameters of the CGWs could be derived.

\subsection{Aqua/AIRS}

The AIRS is a hyperspectral infrared spectrometer onboard the Aqua satellite launched by NASA in 2002 (Aumann et al., 2003). Its spectral measurements cover the wavelength ranges of 3.74$4.61 \mu \mathrm{m}, 6.20-8.22 \mu \mathrm{m}$, and 8.8-15.4 $\mu \mathrm{m}$, with an observation error on the order of $0.2 \mathrm{~K}$. The nominal resolving power of the hyperspectral infrared radiometer is $\lambda / \Delta \lambda=1,200$ (Aumann et al., 2003). The horizontal spatial resolution of AIRS footprints is $13.5 \times$ $13.5 \mathrm{~km}$ at the nadir view and $41 \times 21.4 \mathrm{~km}$ at the scan edges, respectively.Thespectrometercandetectheightsfromthegroundupto 

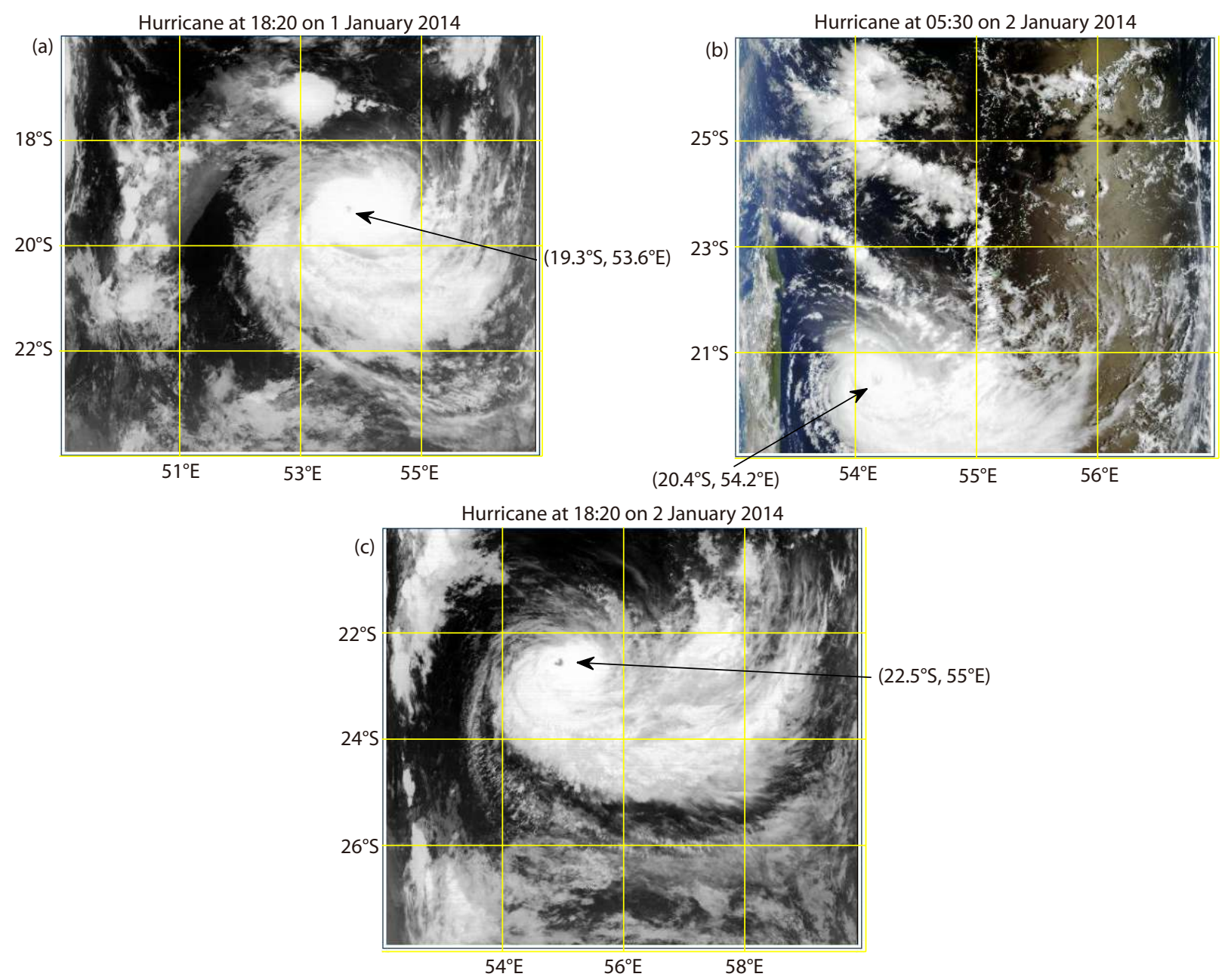

Figure 1. Fengyun polar-orbiting satellite cloud image (a) at 18:20 UTC on 1 January 2014; (b) at 05:30 UTC on 2 January 2014 ; and (c) at 18:20 UTC on 2 January 2014. The clouds are shown in white, and brighter colors indicate a higher cloud top.

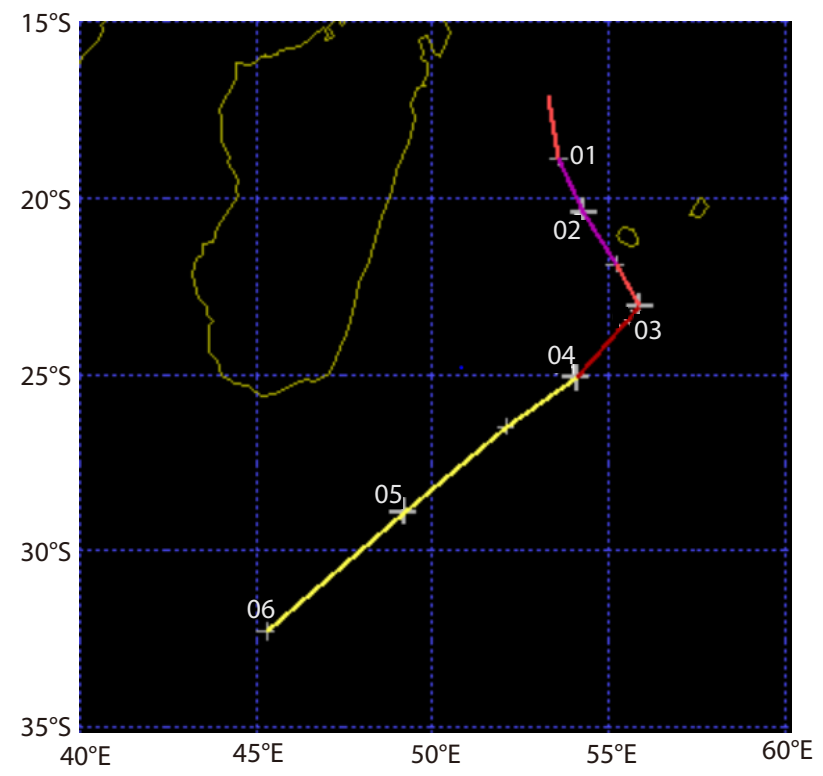

Figure 2. The trajectory of Hurricane Bejisa from observations by the Japan Meteorological Agency from 1 to 6 January 2014.
$65 \mathrm{~km}$. AIRS makes a cross-track scan every $2.67 \mathrm{~s}$ that includes 90 footprints on the ground. The outermost scan angle is $\pm 48.95^{\circ}$ from nadir, which provides a $\sim 1800 \mathrm{~km}$ wide swath given Aqua's $705 \mathrm{~km}$ orbital altitude. The AIRS measurements are gathered in "granules," each of which covers 6 minutes of measurement time, that is, 135 scans or 12,150 footprints. The along-track size of a granule is $2,400 \mathrm{~km}$. The weighting function peaks at different altitudes $(\sim 3-10 \mathrm{hPa})$ of the $15 \mu \mathrm{m}$, and the $4.3 \mu \mathrm{m} \mathrm{CO} 2$ strong absorption band channel radiances can be used to observe the GW activity in the middle and upper atmosphere (Hoffmann and Alexander, 2010; Hoffmann et al., 2013).

The AIRS data were obtained from NASA's Goddard Earth Sciences Data Information and Services Center. In this research, we used the 79th channel radiance of the AIRS instrument to detect the GWs in the stratosphere. The corresponding wavenumber was $667.76 \mathrm{~cm}^{-1}$, and the altitude of the weighting function peak was $41 \mathrm{~km}$. Alexander and Barnet (2007) provided a detailed calculation process between the measured radiance and derived brightness temperature perturbations, as well as the GW amplitudes and wavelengths extracted from these data based on their wavelet analysis. The brightness temperature perturbance was calculated by adopting a classic method. First, the observed brightness 
temperature on each scan line was fitted to the scan angle with a fourth-order polynomial fitting to obtain the background brightness temperature. The observed brightness temperature was then subtracted from the background brightness temperature to obtain the brightness temperature perturbance value (Hoffmann and Alexander, 2010). Through these steps, they were able to remove signals that changed slowly, such as those caused by planetary waves or large temperature gradients (Hoffmann and Alexander, 2010; Hoffmann et al., 2013).

\subsection{Suomi NPP/VIIRS DNB}

The Suomi NPP satellite, which was developed by NASA and is operated by the National Oceanic and Atmospheric Administration (NOAA), was launched on 28 October 2011. The Suomi NPP carries the VIIRS, a 22-band imaging radiometer that measures radiation and the infrared and visible light (Lee et al., 2006; Miller et al., 2013). It is able to collect radiation images from the land, atmosphere, ice, and ocean in the visible/infrared bands. The VIIRS is a scanning optical sensor with a very high spatial resolution of $0.724 \times 0.724 \mathrm{~km}$ and a $12-\mathrm{km}$-long and 3,000-km-wide acrosstrack swath width by synchronous scan. The DNB is a low-light sensor on the next-generation VIIRS; it has a spectral band pass of $505-890 \mathrm{~nm}$. Its sensitivity is 106 times that of most visible light sensors, with observed ground- and lunar-reflected shimmer. The primary source of illumination is atmospheric nightglow emission, predominantly from excited hydroxyl $\left(\mathrm{OH}^{*}\right)$, molecular $\left(\mathrm{O}_{2}\right)$, and atomic oxygen $(\mathrm{O})$. The signal magnitudes range from $10^{-11}$ to $10^{-9} \mathrm{~W} \cdot \mathrm{cm}^{-2} \cdot \mathrm{sr}^{-1}$, or roughly 100 times fainter than moonlight (Miller et al., 2012).

Because the DNB detects the principal nightglow emission layer ( 85-90 km), it can observe the mesoscale GWs (scale of $\sim 10-100$ $\mathrm{km})$ propagating through the free atmosphere or traveling along ducting layers, as well as the large-scale GWs (scale $1,000 \mathrm{~km}$ ) caused by patterns of nightglow variability (Miller et al., 2012). One limitation of the DNB is its coarse time resolution, which provides only one overpass per night at lower latitudes.

Data from the VIIRS sensor data record are distributed by the Cooperative Institute for Meteorological Satellite Studies (CIMSS) Atmosphere Product and Evaluation and Test Element (PEATE) and the NOAA Comprehensive Large Array-data Stewardship System (CLASS). In this research, the DNB detected regions of the direct nightglow emission from near the mesopause $(\sim 85-90 \mathrm{~km})$ to demonstrate the GW phenomenon. As part of the ongoing polarorbit program, the DNB airglow imaging capability with a high spatial resolution enables continuous study of GWs above the stratosphere on a global scale. This continuity provided the opportunity to integrate the DNB with GW observations from other satellite systems.

Table 1 summarizes some of the principal differences between the AIRS and VIIRS/DNB, especially the spectral range of the GWs measured. The principal objective of this comparison is to illustrate the nuances of each measurement in terms of GW sensitivity and characterization and to provide a context for the capabilities and limitations of the AIRS and VIIRS/DNB while contributing to the analysis of GW characteristics. Accuracy was also improved for the VIIRS/DNB compared with the AIRS. Without the higher tem-
Table 1. Comparison between the Aqua/AIRS and the Suomi NPP/VIIRS DNB.

\begin{tabular}{lcc}
\hline Attribute & AIRS & VIIRS/DNB \\
\hline $\begin{array}{l}\text { Technique } \\
\text { Horizontal resolution } \\
(\mathrm{km})\end{array}$ & Spectrometer & Radiometer \\
$\begin{array}{l}\text { Swath width }(\mathrm{km}) \\
\text { Horizontal wavelength } \\
(\mathrm{km})\end{array}$ & 13.5 & 0.75 \\
$\begin{array}{l}\text { Vertical wavelength } \\
(\mathrm{km})\end{array}$ & $50-1,000$ & 3,000 \\
$\begin{array}{l}\text { Temporal coverage } \\
\text { Two overpasses } \\
\text { per day }\end{array}$ & $\begin{array}{c}\text { One overpass per } \\
\text { night }\end{array}$ \\
Altitude $(\mathrm{km})$ & $20-65$ & $85-90$ \\
\hline
\end{tabular}

poral resolution, the AIRS and VIIRS/DNB could have been used to measure only the horizontal wavelength but could not have resolved the wave period and phase velocity. Thus, the vertical wavelength could not have been obtained from the dispersion relationship with only the known horizontal wavelength, which is their limitation.

\subsection{ERA5 Reanalysis Data}

In November 2016, the European Centre for Medium-Range Weather Forecasts (ECMWF) released the first 2-month fifth-generation reanalysis product: the ERA5 (Hersbach and Dee, 2016). ERA5 is produced using 4D-Var data assimilation in CY41R2 of ECMWF's Integrated Forecast System (IFS), with 137 hybrid sigma/pressure (model) levels in the vertical, with the top level at $0.01 \mathrm{hPa}$. Its horizontal and temporal resolutions are $31 \mathrm{~km}$ and $1 \mathrm{~h}$, respectively. In this research, we used the ERA5 reanalysis data from 1 January 2014 and the areas $\left(15-30^{\circ} \mathrm{S}, 40-60^{\circ} \mathrm{E}\right)$ as the atmospheric background wind field in the stratosphere to analyze the GWs. The vertical range was from the surface of the earth to the level at $1 \mathrm{hPa}(\sim 48 \mathrm{~km})$.

\subsection{Horizontal Wind Model}

The seventh-generation HWM (HWM07) is a relatively new empirical model of the horizontal neutral wind from the ground to 500 $\mathrm{km}$ in the Earth's atmosphere. The first edition of the model, released in 1987 (HWM87), was intended for winds at greater than $220 \mathrm{~km}$. The HWM07 is based on wind data obtained from the AEE (Atmospheric Explorer-E) and DE 2 (Dynamics Explorer 2) satellites. The modeling method describes a limited set of meridional and zonal wind components based on space-based and ground-based detection data through the expansion of a vector spherical harmonic function. With the development of the detection level, and with wind data from ground-based incoherent scatter radar and Fabry-Perot optical interferometers, the 1990 model (HWM90) was extended down to $100 \mathrm{~km}$, and with the use of medium-frequency radar and meteor wind data, the 1993 model (HWM93) was extended down to the ground. The latest version of the HWM07 solves some of the defects of HWM90 and HWM93 and can provide global wind field information from the ground to the thermosphere. With the HWM07, we obtained the back- 
ground wind through the use of Matlab with original programs. This research mainly used data at 22:24 UTC on 1 January 2014 at $\left(20^{\circ} \mathrm{S}, 56^{\circ} \mathrm{E}\right)$ in the calm mode.

\section{Analytical Results}

\subsection{Stratospheric CGWs in the AIRS Observation}

Figure 3 shows the AIRS brightness temperature collocated with Hurricane Bejisa as sampled over the period from 1 to 2 January 2014. The red crosses denote the central position of CGWs at 21:08 UTC (Figure 3a) and 10:00 UTC (Figure 3b), approximately when the satellite was passing over the hurricane region. Waves with brightness temperature amplitudes of $1 \mathrm{~K}$ can be seen in Figure 3. To investigate the concentric patterns in greater detail, we fit circles of varying radii and centers to each ring and looked for optimal matches (Yue J et al., 2009; Suzuki et al., 2013). Determining the central position of CGW $1\left(19^{\circ} \mathrm{S}, 53.5^{\circ} \mathrm{E}\right)$ approximated the eye of the hurricane $\left(19.3^{\circ} \mathrm{S}, 53.6^{\circ} \mathrm{E}\right)$ at $18: 20$ UTC (Figure 1a) on 1 January 2014. Similarly, the central position of CGW2 $\left(20.3^{\circ} \mathrm{S}, 54.2^{\circ} \mathrm{E}\right)$ approximated the eye of the hurricane $\left(20.4^{\circ} \mathrm{S}, 54.2^{\circ} \mathrm{E}\right.$ ) at 05:30 UTC (Figure $1 \mathrm{~b}$ ) on 2 January 2014. We estimated the entire wave structure from the fragments of the arc observed by AIRS by assuming that the wave had circular wave fronts that expanded concentrically from a point. According to spherical trigonometry, $R_{k}$ can be written as follows (Suzuki et al., 2013):

$$
R_{k}=R_{\mathrm{e}} \cos ^{-1}\left[\sin \phi_{\mathrm{c}} \sin \phi_{k}+\cos \phi_{\mathrm{c}} \cos \phi_{k} \cos \left(\lambda_{k}-\lambda_{\mathrm{c}}\right)\right]
$$

where $R_{k}$ is the distance from an assumed center at latitude $\lambda_{c}$ and longitude $\phi_{c}$ to the determined point on the $k$ th wave front $\left(\lambda_{k}, \phi_{k}\right)$ and $R_{\mathrm{e}}$ is the radius of the Earth.

The black concentric circles shown in Figure 3a and 3b denote two wave fronts at 21:08 UTC on 1 January 2014 and at 10:00 UTC on 2 January 2014, respectively. The center of the CGW runs along a line $\sim 45^{\circ}$ to the southeast because the arc is clear in this direc-

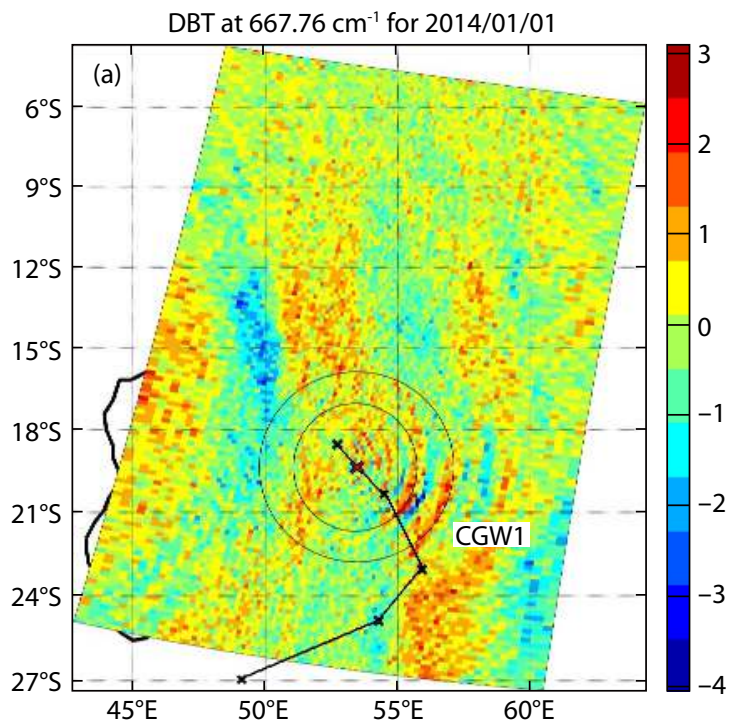

tion. These wave fronts are centered on the deep convection regions of the hurricane, which suggests that CGWs propagating in the stratosphere are associated with Hurricane Bejisa. The radius $R$ is the distance between the eye of the hurricane $\left(19^{\circ} \mathrm{S}, 53.5^{\circ} \mathrm{E}\right)$ and the wave fronts in Figure 3a. The radii were calculated by Equation (1), indicating the stratospheric propagation distance in the horizontal direction, as about $220 \mathrm{~km}$ and $410 \mathrm{~km}$, respectively. We also performed this procedure that calculates the distance between the eye of the hurricane $\left(20.3^{\circ} \mathrm{S}, 54.2^{\circ} \mathrm{E}\right)$ and the wave fronts in Figure $3 \mathrm{~b}$. The characteristics of the CGWs were readily discernable through visual inspection, and the CGWs mainly spread to the southeast, as shown in Figure 3. The horizontal wavelength (the distance between the two wave fronts) of CGW1 was estimated as $\sim 190 \mathrm{~km}(\sim 410-220 \mathrm{~km})$, as shown in Figure 3a. Using the same calculation method, the horizontal wavelength of CGW2 was estimated as $150 \mathrm{~km}(\sim 462-312 \mathrm{~km})$, as shown in Figure 3b. The characteristics of CGWs generated by deep convection were easily recognizable with the naked eye, and the CGWs mainly propagated southeastward. The GWs were initially ring shaped but were changed by strong disturbance winds during upward propagation (Vadas and Fritts, 2009).

\subsection{Mesospheric CGWs in the VIIRS/DNB Observation}

Gravity wave propagation into the mesopause can produce fluctuations in the brightness of the airglow. Figure 4a shows a glimmer image of CGWs over Mauritius $\left(12^{\circ} \mathrm{S}-24^{\circ} \mathrm{S}, 50^{\circ} \mathrm{E}-60^{\circ} \mathrm{E}\right)$ captured by the VIIRS/DNB detector at 22:24 UTC on 1 January 2014. At that moment, two obvious groups of waveforms of this CGW event were chosen, as shown in Figure 4b. The enlarged image of the designated area in Figure $4 \mathrm{~b}$ shows the fit of the arced waveforms in group A and group B. The center of the two groups of CGWs is adjacent to the trajectory of Hurricane Bejisa, thus showing they were part of the same CGW event.

Group A propagated mainly in a southeasterly direction. Above

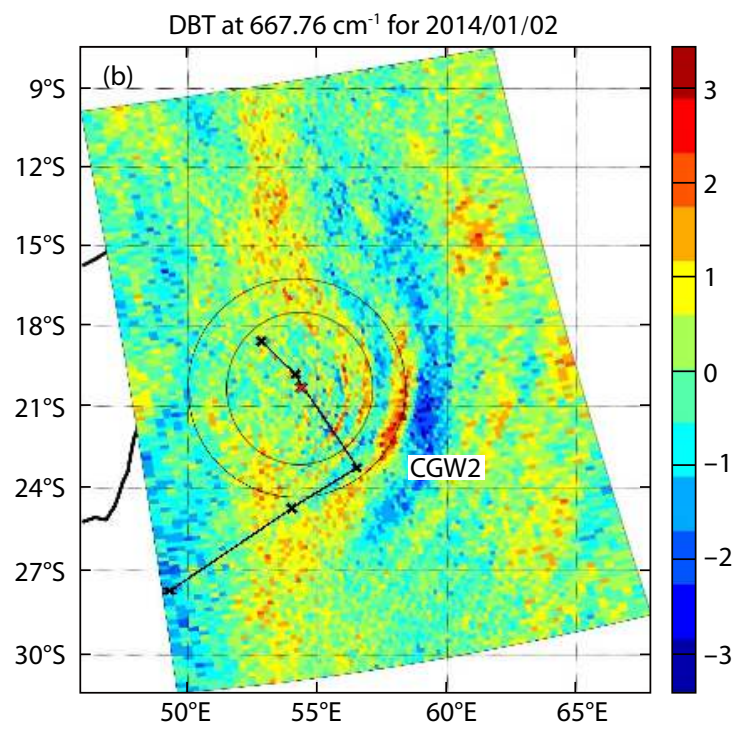

Figure 3. The AIRS disturbance of brightness temperature at the 15- $\mu \mathrm{m}$ band (a) at 21:08 UTC on 1 January 2014 and (b) at 10:00 UTC on 2 January 2014. The black curve is the trajectory of Hurricane Bejisa. The eye of the hurricane is shown with a red cross. The black circles are (a) CGW1 and (b) CGW2, respectively. DBT: Disturbance of Brightness Temperature. 

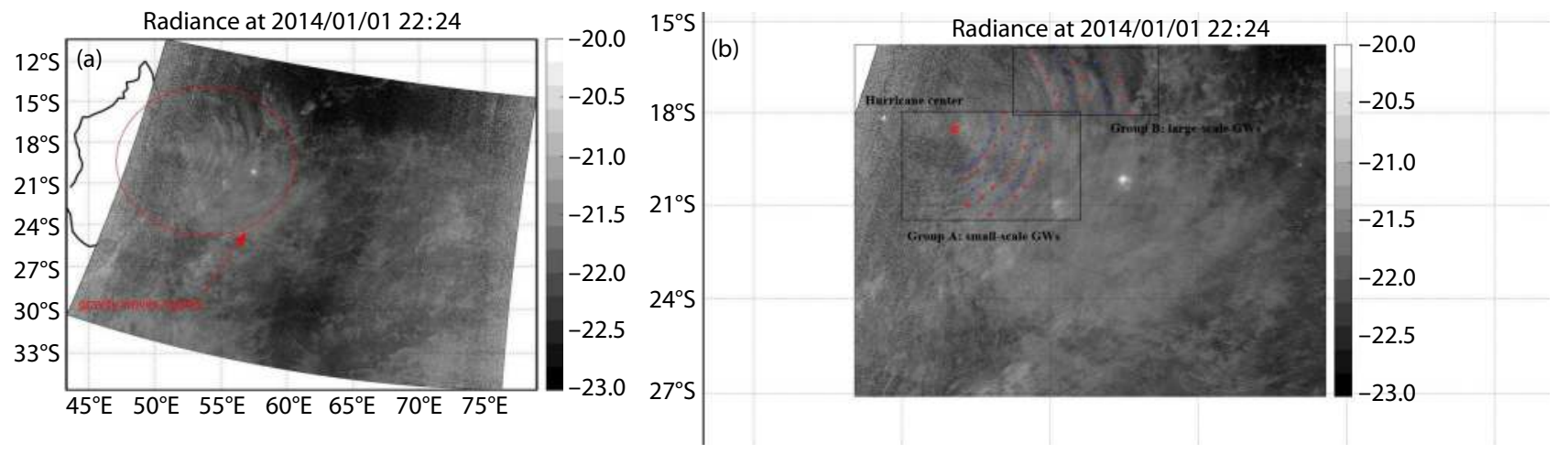

Figure 4. (a) Concentric gravity wave detected by VIIRS/DNB measurements at 22:24 UTC on 1 January 2014. (b) The fit of the arced waveforms in group $A$ and group $B$ is shown in an enlarged image of the designated area (gravity wave ripples). The red cross is the approximate location of the eye of the hurricane. The crests are marked by red dots, and the troughs are marked by blue dots.

the regions affected by Hurricane Bejisa, these small-scale CGWs may have been excited by deep convective activity or strong latent heat release (Kuester et al., 2008; Yue J et al., 2009). This view is consistent with the observation results of AIRS, suggesting that the CGWs originated from the same convective source. The horizontal resolution of VIIRS/DNB was much higher than that of AIRS, so the finer wave structure could be seen in the DNB measurements. For the horizontal wavelengths, values were measured as the distance between two consecutive wave crests in the images (marked by red dots in Figure $4 \mathrm{~b}$ ). The horizontal wavelengths were $\sim 60-70 \mathrm{~km}$.

Group B propagated mainly in a northeasterly direction. Some large-scale wavelength fluctuations can also be seen in Figure $4 b$. These ripple structures are distributed to the northeast of the eye of the hurricane and have horizontal wavelengths of $\sim 150 \mathrm{~km}$. From the distribution of the arc-shaped structure of GWs on the image, we can see both small-scale and large-scale waves, and the horizontal wavelengths were estimated to be roughly $60 \mathrm{~km}$ and $150 \mathrm{~km}$. Group B, with longer horizontal wavelengths, could reach a greater horizontal distance than group $A$.

\subsection{Wave Parameters Derived Together with Background Winds}

Atmospheric GWs can often be described by a simple linear theory that treats them as small departures from a stably stratified background state, varying only vertically. Here we applied the general GW solution to the linearized forms of the fundamental conservation equations. The basic form of the dispersion relationship of GWs was then derived to diagnose further characteristics associated with the GWs (Fritts and Alexander, 2003). The intrinsic frequency $\omega$ is given as the frequency that would be observed in a frame of reference moving with the background wind:

$$
\omega^{2}=\frac{N^{2} k_{h}^{2}+f^{2}\left(m^{2}+\frac{1}{4 H^{2}}\right)}{k_{h}^{2}+m^{2}+\frac{1}{4 H^{2}}}=\left(\omega_{r}-k_{h} \cdot U_{h}\right)^{2}
$$

or

$$
m^{2}=\frac{k_{h}^{2}\left(N^{2}-\omega^{2}\right)}{\omega^{2}-f^{2}}-\frac{1}{4 H^{2}}
$$

where $\omega$ is the intrinsic frequency of the wave and $N$ is the Brunt-Vaisala frequency. The horizontal and vertical wave numbers are $k_{h}=2 \pi / \lambda_{h}$ and $m=2 \pi / \lambda_{z}$, where $\lambda_{h}$ and $\lambda_{z}$ are the horizontal and vertical wavelengths, respectively. Variable $\omega_{r}$ is the ground-based wave frequency, $U_{h}$ is the background horizontal wind in the direction of wave propagation, $f=2 \Omega \sin \phi$ (where $\Omega=$ $2 \pi / 24 \mathrm{hr}$ ) is the Earth's rotational frequency, $\phi$ is the latitude, and $H=7 \mathrm{~km}$ is the scale height.

As discussed in Section 3, the radii and horizontal wavelengths of CGWs were obtained in the stratosphere and mesosphere, as were their horizontal propagation directions. With the dispersion Equation (3), we attempted to derive the other parameters, such as the vertical wavenumber and intrinsic frequency for background winds.

As shown in Figures 3 and 4, the structures of the CGWs changed to an elliptical shape or arced ring pattern, and the GWs were not observed in some regions because of background wind filtering in the stratosphere and mesosphere. The GWs principally propagated in a southeasterly direction, and some of them were filtered. The intrinsic frequency of a GW can be explained by a Doppler shift with background winds:

$$
\omega=\omega_{r}-k_{h} \cdot U_{h}
$$

where $U_{h}$ is the background horizontal wind component along the observed wave propagation direction. Equation (4) can also be expressed as

$$
c=c_{h}-U_{h}
$$

where $c$ and $c_{h}$ are the horizontal intrinsic phase speed and the ground-based phase speed, respectively.

At an altitude of $c_{h}=U_{h}, c$ approaches zero, which suggests the wave can no longer propagate. The level at which $c_{h}=U_{h}$ is called the critical level. According to the linear GW theory, when a GW propagates upward and encounters its critical level, it will be reflected downward or absorbed completely. This GW will be filtered away by the critical level and will not be seen above that level. Therefore, the background winds account for the arc-like CGW structures under the critical-level filtering theory and can provide horizontal phase speed information on the CGW parameters observed in the stratosphere and mesosphere. The value 
ranges of $c_{h}$ and $\omega$ were obtained, depending on the background wind. After $c_{h}$ and $\omega$ were obtained, Equation (3) was used to calculate the vertical wavelength. Finally, the three-dimensional structural parameter of the GW in the stratosphere and mesosphere was obtained.

First, we discuss the effect of the background wind speed on the propagation of GWs from the convective source to the stratosphere. Profiles of the mean zonal and meridional wind with altitude over the hurricane area $\left(15^{\circ} \mathrm{S}-30^{\circ} \mathrm{S}, 40^{\circ} \mathrm{E}-60^{\circ} \mathrm{E}\right)$ at $21: 00$ UTC on 1 January 2014 from the ERA5 data and $U_{h}$ as a function of the altitude and azimuth $\theta$ (in degrees clockwise from the north) are shown in Figure $5 \mathrm{a}$ and $5 \mathrm{~b}$. As shown in Figure 3, azimuths $\theta$ of $30^{\circ}, 45^{\circ}, 60^{\circ}, 75^{\circ}, 90^{\circ}, 105^{\circ}, 120^{\circ}, 135^{\circ}$, and $150^{\circ}$ were the directions of wave propagation observed in the stratosphere ( $z$ of $40 \mathrm{~km}$ ). As shown in Figure 5a, the zonal wind increased from the low stratosphere to the stratosphere with an altitude $z$ of $40 \mathrm{~km}$, and the maximum value was $\sim 42 \mathrm{~m} \cdot \mathrm{s}^{-1}$. The change in the meridional wind was always small, and the wind speed was less than $5 \mathrm{~m} \cdot \mathrm{s}^{-1}$. All the directional winds shown in Figure $5 \mathrm{~b}$ were positive at $12 \mathrm{~km}$ and decreased linearly to negative with increasing height.

The wind speed at an altitude of $40 \mathrm{~km}, U_{z=40 \mathrm{~km}}$, was approximately -24.4 to $-55.3 \mathrm{~m} \cdot \mathrm{s}^{-1}$. For all the directions shown in Figure $5 b$, CGWs were clearly observed in the stratosphere, which suggests that under the critical-level horizontal filtering theory, CGWs had a ground-based phase speed of $c_{h}>0$ and $c_{h}>$ maxim-

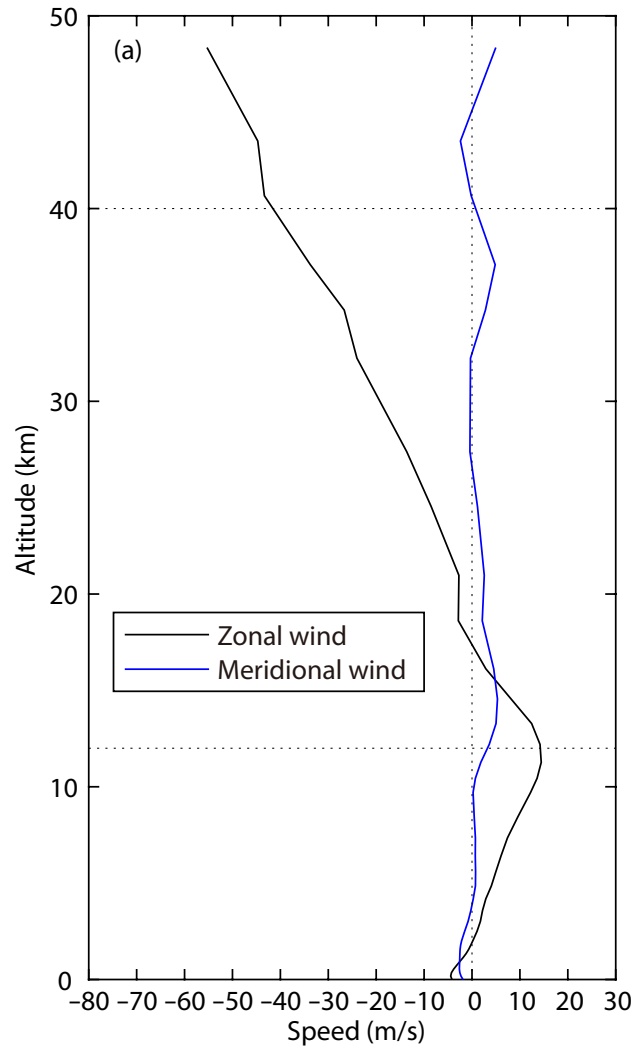

um wind speed (maximum $U_{h}$ ) over altitudes from 12 to $40 \mathrm{~km}$. The maximum $U_{h}$ among the all altitudes and directions was $\sim 14.6 \mathrm{~m} \cdot \mathrm{s}^{-1}$ at $12 \mathrm{~km}$ and the $\theta$ was $75^{\circ}$. Therefore, we can infer from Figure $5 \mathrm{~b}$ that the ground-based phase speed $c_{h}$ must have been greater than $14.6 \mathrm{~m} \cdot \mathrm{s}^{-1}$.

For the directions opposite all the directions shown in Figure 5b, CGWs were not observed clearly in the stratosphere, which suggests a ground-based phase speed of $c_{h}>0$ and $-c_{h}(\theta) \leq$ maximum $\left(-U_{h}(\theta)\right)$, judging that $c_{h} \leq$ minimum $\left(c_{h}(\theta)\right)$ over all the altitudes from 12 to $40 \mathrm{~km}$ under the wind-filtering theory. The minimum $\left(-c_{h}(\theta)\right)$ was $\sim 24.4 \mathrm{~m} \cdot \mathrm{s}^{-1}$ at $40 \mathrm{~km}$, and $\theta$ was $210^{\circ}$. Therefore, it could be inferred that $c_{h}$ must be less than $24.4 \mathrm{~m} \cdot \mathrm{s}^{-1}$. Thus, the ranges obtained for the ground-based phase speed were $14.6 \mathrm{~m} \cdot \mathrm{s}^{-1}<c_{h} \leq 24.4 \mathrm{~m} \cdot \mathrm{s}^{-1}$.

Figure 6 shows the profiles of the mean zonal and meridional wind with altitude over the hurricane area $\left(15^{\circ} \mathrm{S}-30^{\circ} \mathrm{S}, 40^{\circ} \mathrm{E}-60^{\circ} \mathrm{E}\right)$ at 10:00 UTC on 2 January 2014 from the ERA5 data and as a function of the altitude and azimuth $\theta$ (in degrees clockwise from the north). The wind speed at an altitude of $40 \mathrm{~km}, U_{z=40 \mathrm{~km}}$, was approximately -18.5 to $-39.6 \mathrm{~m} \cdot \mathrm{s}^{-1}$. The ranges obtained for the ground-based phase speed were $13.9 \mathrm{~m} \cdot \mathrm{s}^{-1}<c_{h} \leq 18.5 \mathrm{~m} \cdot \mathrm{s}^{-1}$ under the same theory.

According to the preceding analysis, for example, given the direction of $\theta$ of $90^{\circ}$, where $U_{z=40 \mathrm{~km}}=-55.3 \mathrm{~m} \cdot \mathrm{s}^{-1}$ (Figure $5 \mathrm{~b}$ ) and $-39.6 \mathrm{~m} \cdot \mathrm{s}^{-1}$ (Figure $6 \mathrm{~b}$ ), the intrinsic horizontal phase speed $c$

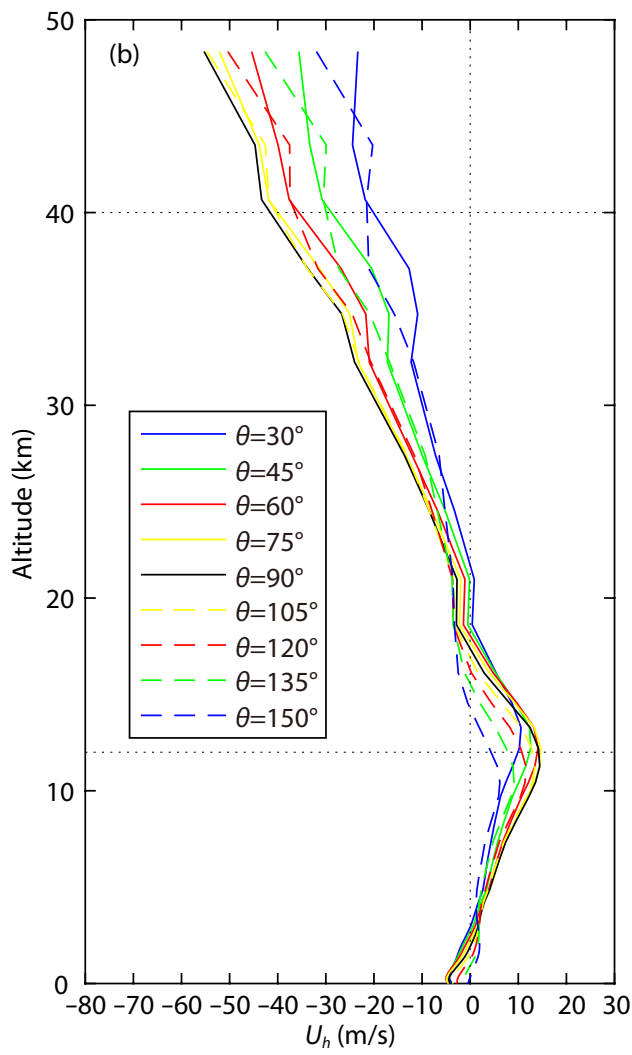

Figure 5. (a) Changes in mean zonal and meridional winds with altitude over the hurricane region (15-30 $\left.\mathrm{S}, 40-60^{\circ} \mathrm{E}\right)$ at $21: 00 \mathrm{UTC}$ on $1 \mathrm{January}$ 2014 from ERA5 data. (A positive zonal wind represents a west wind, and a positive meridional wind represents a south wind.) (b) Background horizontal wind $U_{h}$ as a function of the altitude and azimuth $\theta$ (as shown in degrees clockwise from the north). The solid blue, green, red, yellow, and black curves denote azimuths $\theta$ of $30^{\circ}, 45^{\circ}, 60^{\circ}, 75^{\circ}$, and $90^{\circ}$, and the corresponding dotted curves denote $\theta$ of $105^{\circ}, 120^{\circ}, 135^{\circ}$, and $150^{\circ}$. 

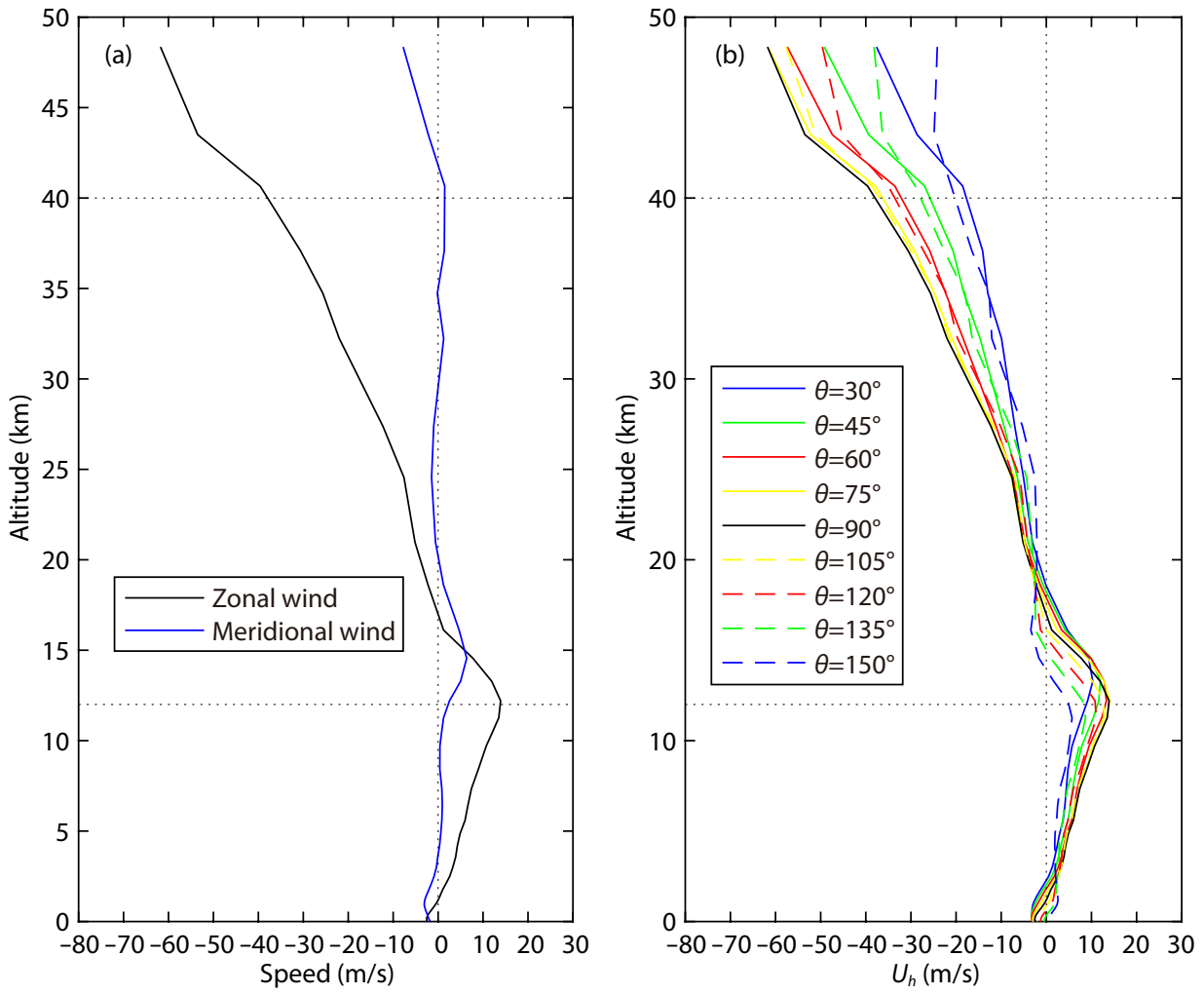

Figure 6. Same presentation as in Figure 5 but at 10:00 UTC on 2 January 2014.

could be estimated as within $\left(69.9 \mathrm{~m} \cdot \mathrm{s}^{-1}, 79.7 \mathrm{~m} \cdot \mathrm{s}^{-1}\right.$ ] and $\left(53.5 \mathrm{~m} \cdot \mathrm{s}^{-1}, 58.1 \mathrm{~m} \cdot \mathrm{s}^{-1}\right.$ ] by Equation (5), and the intrinsic frequency $\omega$ could be calculated by Equation (4) as ( $45 \mathrm{~min}, 40 \mathrm{~min}$ ) and (47 min, $43 \mathrm{~min}$ ). In addition, the calculated vertical wavelengths $\lambda_{z}$ were $(21.12 \mathrm{~km}, 24.34 \mathrm{~km})$ and $(16.00 \mathrm{~km}, 17.41 \mathrm{~km})$ for CGW1 and CGW2, respectively.

Second, we discuss what changes in the background wind speed influenced results in the mesosphere. Profiles of the mean zonal and meridional winds with altitude from the eye of the hurricane $\left(19.3^{\circ} \mathrm{S}, 56.6^{\circ} \mathrm{E}\right)$ at 22:24 UTC on 1 January 2014 using HWM07 model data and $U_{h}$ as a function of altitude and azimuth $\theta$ are shown in Figure $7 \mathrm{a}$ and $7 \mathrm{~b}$. As shown in Figure $7 \mathrm{~b}, \theta$ of $45^{\circ}, 60^{\circ}$, $75^{\circ}, 90^{\circ}, 105^{\circ}, 120^{\circ}$, and $135^{\circ}$ were the directions of wave propagation in the mesosphere ( $z$ of $87 \mathrm{~km}$ ). Similar to the preceding process, we could infer that the horizontal phase speed of CGWs with a horizontal wavelength of $60 \mathrm{~km}$ for small-scale waves or $150 \mathrm{~km}$ for large-scale waves could be derived as within $8 \mathrm{~m} \cdot \mathrm{s}^{-1}<c_{h} \leq$ $43 \mathrm{~m} \cdot \mathrm{s}^{-1}$.

On the basis of the preceding analysis, for example, taken the direction of $\theta=135^{\circ}$ (small-scale waves) and $\theta=75^{\circ}$ (large-scale waves), where $U_{z=87 \mathrm{~km}}=-15 \mathrm{~m} \cdot \mathrm{s}^{-1}$ and $-13 \mathrm{~m} \cdot \mathrm{s}^{-1}$, the intrinsic horizontal phase speed $c$ could be estimated as within $\left(23 \mathrm{~m} \cdot \mathrm{s}^{-1}\right.$, $58 \mathrm{~m} \cdot \mathrm{s}^{-1}$ ) and $\left(21 \mathrm{~m} \cdot \mathrm{s}^{-1}, 56 \mathrm{~m} \cdot \mathrm{s}^{-1}\right.$ ] by Equation (9), and the intrinsic frequency $\omega$ could be calculated as (43 $\mathrm{min}, 17 \mathrm{~min}$ ) and (119 min, $45 \mathrm{~min}$ ) by Equation (8). In addition, the calculated vertical wavelengths $\lambda_{z}$ were $(6.98 \mathrm{~km}, 18.63 \mathrm{~km})$ and $(6.31 \mathrm{~km}, 17.26 \mathrm{~km})$, for the small-scale $(\sim 60 \mathrm{~km})$ and large-scale $(\sim 150 \mathrm{~km})$ waves, respectively. Table 2 shows the calculation results for wave parameters observed at different altitudes, depending on the back- ground wind.

Despite the comparatively coarse resolution of the AIRS data, the horizontal wavelengths and propagation directions of these GWs are known. Wave periods or velocities could not be determined by AIRS. Using the method above, we estimated the vertical wavelength of the southeast-propagating CGW1 as 21-24 km (Table 2). In this study, we used the 79th channel radiance of the AIRS, and the corresponding wavenumber was $667.76 \mathrm{~cm}^{-1}$. It was difficult to capture waves with a vertical wavelength of less than $12 \mathrm{~km}$ by AIRS. We can confidently say that the vertical wavelengths must be greater than 15-20 km because of the lower detection threshold of AIRS (Hoffmann and Alexander, 2010). For later calculations, we used an average vertical wavelength of $23 \mathrm{~km}$ and a horizontal wavelength of $190 \mathrm{~km}$. Because the generation mechanism of GWs is deep convection, we assumed that GWs are emitted from the tropopause (about $12 \mathrm{~km}$ in this study). This was a good assumption because the fluid below the tropopause is generally unstable when convection is occurring and therefore cannot support the propagation of GWs below the deep convection. Because it takes minutes for GWs with long vertical and short horizontal wavelengths to travel upward from their convective sources near the tropopause to $\sim 40 \mathrm{~km}$ altitude, these GWs were actually excited by the hurricane earlier than 21:08 UTC on 1 January within the same deep convective system.

Gravity waves are quite dispersive in the atmosphere. As illustrated in Figures 3 and 4, when GWs propagate from the convective source into higher altitudes, they spread to a larger area on the horizontal plane. Gravity waves with different periods have different propagation zenith angles and radii. To estimate the propaga- 

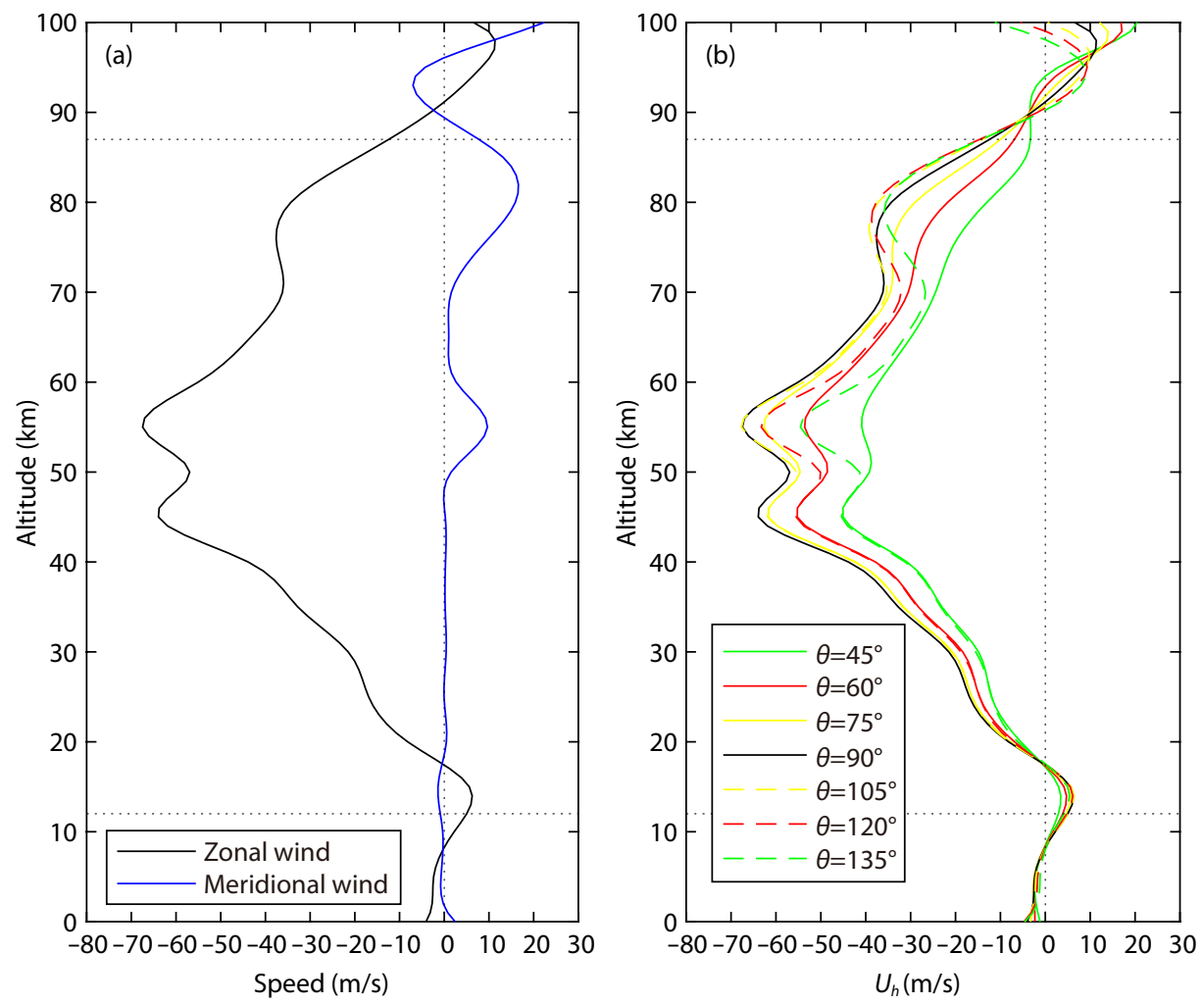

Figure 7. (a) Changes in mean zonal and meridional winds with altitude from the eye of the hurricane $\left(19.3^{\circ} \mathrm{S}, 56.6^{\circ} \mathrm{E}\right)$ at $22: 24 \mathrm{UTC}$ on 1 January 2014 by using HWM07 model data. (b) Background horizontal wind $U_{h}$ as a function of the altitude and azimuth $\theta$. The green, red, yellow, and black solid curves denote azimuths $\theta$ of $45^{\circ}, 60^{\circ}, 75^{\circ}$, and $90^{\circ}$, and the corresponding dashed curves denote $\theta$ of $105^{\circ}, 120^{\circ}$, and $135^{\circ}$.

Table 2. Results calculated for concentric gravity wave (CGW) parameters of the stratosphere and mesosphere.

\begin{tabular}{|c|c|c|c|c|c|}
\hline$\lambda_{h}(\mathrm{~km})$ & $c_{h}\left(m \cdot s^{-1}\right)$ & $c\left(m \cdot s^{-1}\right)$ & Intrinsic period (min) & $\begin{array}{c}\text { Intrinsic } \\
\text { frequency }(\mathrm{Hz})\end{array}$ & $\lambda_{z}(\mathrm{~km})$ \\
\hline \multicolumn{6}{|c|}{ Altitude $z=40 \mathrm{~km}, N=0.0215 \mathrm{~s}^{-1}, \theta=90^{\circ}$} \\
\hline 150 (CGW2) & $(13.9,18.5]$ & $(53.5,58.1]$ & $(47,43)$ & $(0.0022,0.0024)$ & $(16.00,17.41)$ \\
\hline \multicolumn{6}{|c|}{ Altitude $z=87 \mathrm{~km}, N=0.0209 \mathrm{~s}^{-1}, \theta=75^{\circ}$ and $\theta=135^{\circ}$} \\
\hline 150 (large-scale wave) & $(8,43]$ & $(21,56]$ & $(119,45)$ & $(0.00088,0.0023)$ & $(6.31,17.26)$ \\
\hline
\end{tabular}

tion time of the GWs propagating from the stratosphere to the mesosphere, we first calculated the vertical group velocity $c_{g z}$ by using Equation (6) (Fritts and Alexander, 2003):

$$
c_{g z}=-\frac{N k_{h} m}{\left(k_{h}^{2}+m^{2}+\frac{1}{4 H^{2}}\right)^{3 / 2}}
$$

where $c_{g z}$ was estimated as $8 \mathrm{~m} \cdot \mathrm{s}^{-1}$, given that $\lambda_{h}=2 \pi / \mathrm{k}_{h}$ is $190 \mathrm{~km}$ and $\lambda_{z}=2 \pi / \mathrm{m}$ is $23 \mathrm{~km}$. The Brunt-Vaisala frequency $N$ is $2 \pi / 5 \mathrm{~min}^{-1}$. Thus, to propagate from $\sim 40 \mathrm{~km}$, where the AIRS GW measurements took place, to $\sim 87 \mathrm{~km}$, where the DNB measurements were taken, took about $98 \mathrm{~min}$. The GWs seen in the AIRS observations at 21:08 UTC should therefore appear in the DNB images around 22:46 UTC. However, the GWs observed by the DNB imaging at 22.24 UTC were likely not the same GWs as seen by AIRS, although they were likely to have been excited by the same convective source.

As shown in Table 2, note that the calculated vertical wavelengths of the smale-scale and large-scale CGWs in the mesosphere had lower vertical wavelength limits of greater than $6.98 \mathrm{~km}$ and $6.92 \mathrm{~km}$, respectively. According to the existing research (Yue J et al., 2014), CGWs excited by tropical cyclones should be observed by the DNB as having vertical wavelengths of more than $10 \mathrm{~km}$ because of the thick airglow layer. If we adopt the lower limit that $\lambda_{z}>10 \mathrm{~km}$ because of the airglow layer, through the theoretical calculation, the lower limit of the ground-based horizontal phase speed of CGWs detected by the DNB could be $c_{h}>25 \mathrm{~m} \cdot \mathrm{s}^{-1}$. Most of the differences in results between the stratosphere and mesosphere could be explained by Doppler shifting by the convective source. The calculated results in Table 2 show that the wind speed at the tropopause played an important role in the GW parameters 
in the stratosphere and the mesosphere. Research by Zhang SD and Yi F (2007) indicated that the tropospheric jet is the most important excitation source for GWs in both the troposphere and lower stratosphere and that it plays different roles in determining the morphology of GWs in these two segments. These results suggest that to attain a more realistic source parameterization for GWs propagating in the middle and upper atmosphere, more attention should be paid to characterizing the troposphere. By measuring the background wind field and GW parameters more accurately with sophisticated and comprehensive instrumentation (lidar, radar, and satellite sensors) can reduce additional assumptions and study the detailed process of vertical propagation of GWs generated by deep convection.

\section{Conclusions}

In this research, we analyzed the simultaneous observations of CGWs in the stratosphere and mesosphere generated by Hurricane Bejisa over the island of Mauritius on 1 January 2014 in an effort to present a new case of CGWs generated by a hurricane. In addition, we attempted for the first time to derive all the parameters of the CGWs from the AIRS and DNB data sets, ERA5 reanalysis data, and HWM07 empirical model.

The horizontal wavelengths of the satellite-observed GWs were estimated as approximately $190 \mathrm{~km}$ and $150 \mathrm{~km}$ for the two cases of CGW1 and CGW2 in the stratosphere and as $60 \mathrm{~km}$ for the small-scale waves and $150 \mathrm{~km}$ for the large-scale waves in the mesosphere.

In reality, the background wind speeds change with altitude; thus, the functions of the critical-level filter of CGWs and Doppler effect propagation processes were analyzed with the stratosphere and mesosphere winds. The ERA5 data and HWM07 model data were used to determine the background horizontal wind component at the observed altitude of waves along the wave propagation direction. From the conditions of background wind speed in multiple propagation directions, we estimated the ground-based phase speed, intrinsic phase speed, period, and vertical wavelength for the observed CGWs in the stratosphere and mesosphere. The characteristics of these parameters provided further information on the multilayer couplings through vertical wave propagation. According to the vertical wavelengths at $\sim 21-24 \mathrm{~km}$ in the stratosphere, the images in the AIRS and DNB data may not show exactly the same GWs because the time offset between the different observations may not match the exact propagation time from the stratosphere to the mesosphere. Just $\sim 22 \mathrm{~min}$ before the AIRS observation, VIIRS/DNB observed both the small-scale and largescale CGWs with horizontal wavelengths of $\sim 60 \mathrm{~km}$ and $\sim 150 \mathrm{~km}$ simultaneously in the nightglow structures. Therefore, the morphology and time of the altitudes of observed GWs suggest that they were likely excited by the same convective system, but further confirmation is needed that they were produced by the same convective source.

\section{Acknowledgments}

Thanks are extended to Xiong Hu for his guidance and many suggestions and to Mingcheng Sun for his helpful discussion on data processing and using HWM07. This research is supported by the Strategic Priority Research Program of Chinese Academy of Sciences (no. XDA17010301) and the National Key Research and Development Program of China (no. 2016YFB0501503). It is also a project of the National Natural Science Foundation of China (nos. $4190503811872128,91952111,41575031)$ and part of the China Postdoctoral Foundation Program (no. 2015M580124). We would also like to thank the National Satellite Center for providing the satellite cloud images. The AIRS data were obtained from NASA's Goddard Earth Sciences Data Information and Services Center. The AIRS data used in this study can be obtained from the following website: https://bou.class.noaa.gov/. The VIIRS sensor data record data are distributed by the CIMSS PEATE and NOAA CLASS from the following website: https://worldview.earthdata.nasa. gov/. The ERA5 reanalysis data were provided by the ECMWF. The data products used in this study can be obtained from the Copernicus Climate Data Store: https://cds.climate.copernicus.eu/.

\section{References}

Alexander, M. J., and Holton, J. R. (1997). A model study of zonal forcing in the equatorial stratosphere by convectively induced gravity waves. J. Atmos. Sci., 54(3), 408-419. https://doi.org/10.1175/15200469(1997)054<0408:AMSOZF>2.0.CO;2

Alexander, M. J., and Rosenlof, K. H. (2003). Gravity-wave forcing in the stratosphere: Observational constraints from the Upper Atmosphere Research Satellite and implications for parameterization in global models. J. Geophys. Res. Atmos., 108(D19), 4597.

https://doi.org/10.1029/2003JD003373

Alexander, M. J., May, P. T., and Beres, J. H. (2004). Gravity waves generated by convection in the Darwin area during the Darwin Area Wave Experiment. J. Geophys. Res. Atmos., 109(D20), D20S04. https://doi.org/10.1029/2004JD004729

Alexander, M. J., and Barnet, C. (2007). Using satellite observations to constrain parameterizations of gravity wave effects for global models. J. Atmos. Sci., 64(5), 1652-1665. https://doi.org/10.1175/JAS3897.1

Alexander, M. J., and Teitelbaum, H. (2007). Observation and analysis of a large amplitude mountain wave event over the Antarctic Peninsula. J. Geophys. Res. Atmos., 112(D21), D21103. https://doi.org/10.1029/2006JD008368

Alexander, M. J., Geller, M., McLandress, C., Polavarapu, S., Preusse, P., Sassi, F., Sato, K., Eckermann, S., Ern, M., ... Watanabe, S. (2010). Recent developments in gravity-wave effects in climate models and the global distribution of gravity-wave momentum flux from observations and models. Quart. J. Roy. Meteor. Soc., 136(650), 1103-1124. https://doi.org/10.1002/qj.637

Aumann, H. H., Chahine, M. T., Gautier, C., Goldberg, M. D., Kalnay, E., McMillin, L. M., Revercomb, H., Rosenkranz, P. W., Smith, W. L., ... Susskind, J. (2003). AIRS/AMSU/HSB on the Aqua mission: Design, science objectives, data products, and processing systems. IEEE Trans. Geosci. Remote Sens., 41(2), 253-264. https://doi.org/10.1109/TGRS.2002.808356

Charron, M., and Manzini, E. (2002). Gravity waves from fronts: parameterization and middle atmosphere response in a general circulation model. J. Atmos. Sci., 59(5), 923-941. https://doi.org/10.1175/15200469(2002)059<0923:GWFFPA>2.0.CO;2

Fritts, D. C., and Alexander, M. J. (2003). Gravity wave dynamics and effects in the middle atmosphere. Rev. Geophys., 41(1), 1003. https://doi.org/10.1029/2001RG000106

Gong, J., Yue, J., and Wu, D. L. (2015). Global survey of concentric gravity waves in AIRS images and ECMWF analysis. J. Geophys. Res. Atmos., 120(6), 2210-2228. https://doi.org/10.1002/2014JD022527

Heale, C. J., Bossert, K., Snively, J. B., Fritts, D. C., Pautet, P. D., and Taylor, M. J. (2017). Numerical modeling of a multiscale gravity wave event and its airglow signatures over Mount Cook, New Zealand, during the DEEPWAVE 
campaign. J. Geophys. Res. Atmos., 122(2), 846-860.

https://doi.org/10.1002/2016JD025700

Hersbach, D., and Dee, D. (2016). ERA5 reanalysis is in production. ECMWF Newsletter., 147.

Hoffmann, L., and Alexander, M. J. (2010). Occurrence frequency of convective gravity waves during the North American thunderstorm season. J. Geophys. Res. Atmos., 115(D20), D20111. https://doi.org/10.1029/2010JD014401

Hoffmann, L., Xue, X., and Alexander, M. J. (2013). A global view of stratospheric gravity wave hotspots located with Atmospheric Infrared Sounder observations. J. Geophys. Res. Atmos., 118(2), 416-434. https://doi.org/10.1029/2012JD018658

Huang, K. M., Zhang, S. D., Fan, Y., and Chen, Z. Y. (2009). Simulation of the equatorial quasi-biennial oscillation based on the parameterization of continuously spectral gravity waves. Chin. Sci. Bull, 54(2), 288-295. https://doi.org/10.1007/s11434-008-0409-z

Kaifler, B., Kaifler, N., Ehard, B., Dörnbrack, A., Rapp, M., and Fritts, D. C. (2015). Influences of source conditions on mountain wave penetration into the stratosphere and mesosphere. Geophys. Res. Lett., 42(21), 9488-9494. https://doi.org/10.1002/2015GL066465

Kim, S. Y., Chun, H. Y., and Wu, D. L. (2009). A study on stratospheric gravity waves generated by Typhoon Ewiniar: Numerical simulations and satellite observations. J. Geophys. Res. Atmos., 114(D22), D22104. https://doi.org/10.1029/2009JD011971

Kim, S. Y., and Chun, H. Y. (2010). Stratospheric gravity waves generated by Typhoon Saomai (2006): Numerical modeling in a moving frame following the typhoon. J. Atmos. Sci., 67(11), 3617-3636. https://doi.org/10.1175/2010JAS3374.1

Kuester, M. A., Alexander, M. J., and Ray, E. A. (2008). A model study of gravity waves over Hurricane Humberto (2001). J. Atmos. Sci., 65(10), 3231-3246. https://doi.org/10.1175/2008JAS2372.1

Lee, T. E., Miller, S. D., Turk, F. J., Schueler, C., Julian, R., Deyo, S., Dills, P., and Wang, S. (2006). The NPOESS VIIRS day/night visible sensor. Bull. Amer. Meteor. Soc., 87(2), 191-200. https://doi.org/10.1175/BAMS-87-2-191

Liu, X., Xu, J., Liu, H. L., Yue, J., and Yuan, W. (2014). Simulations of large winds and wind shears induced by gravity wave breaking in the mesosphere and lower thermosphere (MLT) region. Ann. Geophys., 32(5), 543-552. https://doi.org/10.5194/angeo-32-543-2014

Miller, S. D., Mills, S. P., Elvidge, C. D., Lindsey, T., Lee, T. F., and Hawkins, J. D. (2012). Suomi satellite brings to light a unique frontier of nighttime environmental sensing capabilities. Proc. Natl. Acad. Sci. USA, 109(39), 15706-15711. https://doi.org/10.1073/pnas.1207034109

Miller, S. D., Straka III, W., Mills, S. P., Elvidge, C. D., Lee, T. F., Solbrig, J., Walther, A., Heidinger, A. K., and Weiss, S. (2013). Illuminating the capabilities of the Suomi National Polar-Orbiting Partnership (NPP) Visible Infrared Imaging Radiometer Suite (VIIRS) Day/Night Band. Remote Sens., 5(12), 6717-6766. https://doi.org/10.3390/rs5126717

Perwitasari, S., Sakanoi, T., Nakamura, T., Ejiri, M. K., Tsutsumi, M., Tomikawa, Y., Otsuka, Y., Yamazaki, A., and Saito, A. (2016). Three years of concentric gravity wave variability in the mesopause as observed by IMAP/VISI. Geophys. Res. Lett., 43(22), 11528-11535.
https://doi.org/10.1002/2016GL071511

Piani, C., Durran, D., Alexander, M. J., and Holton, J. R. (2000). A numerical study of three-dimensional gravity waves triggered by deep tropical convection and their role in the dynamics of the QBO. J. Atmos. Sci., 57(22), 3689-3702. https://doi.org/10.1175/1520-0469(2000)057<3689:ANSOTD>2.0.CO;2

Stephan, C., Alexander, M. J., and Richter, J. H. (2016). Characteristics of gravity waves from convection and implications for their parameterization in global circulation models. J. Atmos. Sci., 73(7), 2729-2742. https://doi.org/10.1175/JAS-D-15-0303.1

Suzuki, S., Vadas, S. L., Shiokawa, K., Otsuka, Y., Kawamura, S., and Murayama, Y. (2013). Typhoon-induced concentric airglow structures in the mesopause region. Geophys. Res. Lett., 40(22), 5983-5987. https://doi.org/10.1002/2013GL058087

Vadas, S. L., and Fritts, D. C. (2009). Reconstruction of the gravity wave field from convective plumes via ray tracing. Ann. Geophys., 27(1), 147-177. https://doi.org/10.5194/angeo-27-147-2009

Vadas, S. L., and Becker, E. (2018). Numerical modeling of the excitation, propagation, and dissipation of primary and secondary gravity waves during Wintertime at McMurdo Station in the Antarctic. J. Geophys. Res. Atmos., 123(17), 9326-9369. https://doi.org/10.1029/2017JD027974

Vadas, S. L., Zhao, J., Chu, X. Z., and Becker, E. (2018). The excitation of secondary gravity waves from local body forces: theory and observation. $J$. Geophys. Res. Atmos., 123(17), 9296-9325. https://doi.org/10.1029/2017JD027970

Xu, S., Yue, J., Xue, X. H., Vadas, S. L., Miller, S. D., Azeem, I., Straka III, W., Hoffmann, L., and Zhang, S. M. (2019). Dynamical coupling between hurricane matthew and the middle to upper atmosphere via gravity waves. J. Geophys. Res.: Space Phys., 124(5), 3589-3608. https://doi.org/10.1029/2018JA026453

Yamashita, C., Liu, H. L., and Chu, X. Z. (2010). Responses of mesosphere and lower thermosphere temperatures to gravity wave forcing during stratospheric sudden warming. Geophys. Res. Lett., 37(9), L09803. https://doi.org/10.1029/2009GL042351

Yue, J., Vadas, S. L., She, C. Y., Nakamura, T., Reising, S. C., Liu, H. L., Stamus, P., Krueger, D. A., Lyons, W., and Li, T. (2009). Concentric gravity waves in the mesosphere generated by deep convective plumes in the lower atmosphere near Fort Collins, Colorado. J. Geophys. Res. Atmos., 114(D6), D06104. https://doi.org/10.1029/2008JD011244

Yue, J., Hoffmann, L., and Alexander, M. J. (2013). Simultaneous observations of convective gravity waves from a ground-based airglow imager and the AIRS satellite experiment. J. Geophys. Res. Atmos., 118(8), 3178-3191. https://doi.org/10.1002/jgrd.50341

Yue, J., Miller, S. D., Hoffmann, L., and Strakalll, W. C. (2014). Stratospheric and mesospheric concentric gravity waves over Tropical Cyclone Mahasen: Joint AIRS and VIIRS satellite observations. J. Atmos. Sol.-Terr. Phys., 119, 83-90. https://doi.org/10.1016/j.jastp.2014.07.003

Zhang, S. D., and Yi, F. (2007). Latitudinal and seasonal variations of inertial gravity wave activity in the lower atmosphere over central China. J. Geophys. Res. Atmos., 112(D5), D05109. https://doi.org/10.1029/2006JD007487 